\title{
Genetic Diversity Studies of Popular Rice Varieties based on Grain Quality Characters
}

\author{
H. N. Subudhi, J. Meher, S. K. Dash, L. K. Bose, Sutapa Sarkar and S. Mohapatra* \\ National Rice Research Institute, Cuttack, Odisha, India \\ *Corresponding author
}

\section{A B S T R A C T}

\begin{tabular}{|l|}
\hline Ke y w o r d s \\
$\begin{array}{l}\text { Diversity, Quality } \\
\text { characters, Rice } \\
\text { varieties }\end{array}$ \\
\hline Article Info \\
\hline $\begin{array}{l}\text { Accepted: } \\
\text { 18 December } 2020 \\
\text { Available Online: } \\
\text { 10 January 2021 }\end{array}$ \\
\hline
\end{tabular}

One hundred rice genotypes released for different ecologies such as upland, irrigated, lowland, and saline in different states of India were evaluated for 12 quality characters like Hulling (\%), Milling (\%), Head rice recovery(\%), Kernel length(cm), Kernel breadth(cm), Length breadth ratio, Volume expansion ratio, Elongation ratio and Amylose content $(\%)$ etc to study the magnitude of genetic diversity among the genotypes and major traits contributing to variation. Based on Mahalanobis $\mathrm{D}^{2}$ value, 100 genotypes are grouped in to 12 clusters. The single genotype having independent cluster are WITA-8, WGL32183, Konark, Purnendu, VLD-61, PusaSugandh-3 and Improved Lalat. Maximum 55 genotypes are in cluster 1. Maximum inter cluster divergence was observed between cluster 3 and 11(667.36) followed by cluster 8 and 11(615.50), cluster 7and 11(604.87). Lowest inter cluster distance was observed between cluster 2and 3(10.68).Intra cluster distance (D) ranged from 48.77 (cluster 5) to 100.4 (cluster 8 ). These are more diverse and can be used in hybridisation programme for development of effective hybrids. The inter cluster distance is higher than intra cluster distance indicating wide genetic diversity among the genotypes.

\section{Introduction}

Rice is the staple food for more than half of the world population and number one human food crop in the world.(Itani, 2002). Rice occupies a pivotal role in Indian food and livelihood security. India is the second most populous nation and stand first in areas and second in production followed by China. In India, 44.6Mha are in rice cultivation. It is grown in all continent and in all agro-climatic zones. These wide adaptations lead to evolution of thousands of varieties having diverse cooking and eating characters. Before 2000AD, there is demand for increase in production and productivity to meet the food requirement of the growing population. There after, India became self sufficient and surplus country so far as rice is concerned. People became more concerned about quality rather than quantity. Previously breed varieties are mostly bold grain, which people do not like. India has released 705 varieties without testing quality characters (Thongbam et al., 2010). Now quality characters are considered during the varietal development and release. 
Quality is very important determinant of market price, consumer acceptance and end users. Consumers preference depend on appearance, milling and cooking process, grain shape and size. Grain quality in rice is determined by grain appearance nutritional value, cooking and eating quality (Juliano et al., 1990).Good grain quality fetches high market price. So demand for better grain quality is increasing day by day in developing and developed countries. Now quality is an important breeding objective in all rice breeding programme. Sobha Rani et al., (2008) studied the quality characters of 78 varieties of India. There after 28 land races of Assam were evaluated by Das and Borah, (2008). Realising the importance, Bhonsle and Sellapan (2010) evaluated 22 traditional varieties of Goa for their physico-chemical characters. Vanaja and Babu (2006) studied 56 high yielding varieties of Kerala. Shrivastava et al., (2012) also evaluated 12 genotypes of Faizabad. Subudhi et al., (2012) evaluated 42 released varieties of Odisha for their quality characters and their variations. It is evident that there is no systematic study of grain quality characters for released varieties in India. Now attempts have been made to evaluate the released varieties for their quality characters to find out better donors for hybridisation, popularisation and development of database. In the preliminary study, 100 genotypes of different states and for different ecologies were evaluated to find out better donors for hybridisation and analysis of their diversity.

\section{Materials and Methods}

The experiment was conducted in the farm of National Rice Research Institute, Cuttack during Kharif 2017.One hundred released rice varieties for different states in India of different ecologies viz., upland (17), medium (50) and lowland (30), saline (3)were transplanted in randomised block design with two replications. 25 days old seedlings were transplanted with spacing $15 \times 20 \mathrm{~cm}$. The recommended dose of $\mathrm{N}: \mathrm{P}: \mathrm{K}(80: 40: 40)$ were applied. All the agronomic practices were followed to raise good crop.

\section{Methods}

After 3 months of harvest, Samples were cleaned thoroughly using winnower to remove chaff and other foreign matters and dried up to $12-14 \%$ moisture content. Analysis of all quality traits were done in two replications.

\section{Physical properties}

Kernel length, kernel breadth, and kernel length breadth ratio were measured by dial micrometer(Ramiah,1969).Hulling (\%) and Milling (\%) were done by using standard rice huller (SatakeThuza) and rice polisher (Satake TMO5A) respectively. After cleaning and weighing the dehusked kernel(brown rice), Hulling (\%) was calculated. Dehusked kernel were polished to remove bran and Milling (\%) was calculated. Head rice recovery $(\%)$ were calculated (Govindswamy and Ghosh, 1969).

Chemical properties: Alkali spreading value was analysed following Little et al., (1958). Amylase content was calculated (Juliano, 1971).

Cooking characters: Water uptake and Volume expansion ratio were done (Anonymous, 2004), (Beachell and Stanse, 1963). Similarly kernel length after cooking were measured following Azeez and Shafi (1966). All the pooled data were analysed statistically (Gomez and Gomez, 1984).

\section{Results and Discussion}

Based Mahalanobis $\mathrm{D}^{2}$ value, 100 genotypes are grouped in to 12 clusters (Fig-1) 
maximum 55 genotypes are in cluster 1 followed by 19 genotypes (cluster-4), 12genotypes (cluster-8), 4 genotypes (cluster5), 3genotypes (cluster-11). But the cluster viz., 2,3,6,7,9,10, and 12 are represented by single genotype. The single genotype viz., WITA-8, WGL32183, Konark, Purnendu, VLD-61, Pusasugandh-3 and Improved Lalat are more diverse and can be used in hybridisation for effective result.

The inter cluster distance is higher than intra cluster distance indicating wide genetic diversity among the genotypes. The highest intra cluster distance is observed in cluster 8 (100.04) followed by 11(86.66), cluster IV(69.94), cluster-1(57.2). The intra cluster distance is zero in cluster $-7,9,10$ and 12 as these clusters are represented by single genotype.

The inter cluster distance is lowest between cluster-2 and 3(10.68) followed by cluster 3 and 7(49.75), cluster2 and 7 (59.73).Highest inter cluster distance was observed in cluster3 and 11(667.36) followed by cluster 8 and
11(615.50), cluster 7 and 11(604.87), cluster 2 and 11(598.87), cluster 7 and 10(584). Hybridisation between the genotypes having low inter cluster distance are not effective whereas hybridisation between highest cluster mean can provide very good result (Fig-2).

\section{Cluster mean}

Cluster mean for hulling (\%) is highest in cluster 12(81.0) and lowest incluster 5(76.6). For Milling (\%), cluster 6 is having maximum value (72.0) and cluster 3 is having minimum value (65.5). For HRR (\%), highest mean value is in cluster $8(61.5)$ and lowest in cluster 6(42.5). Highest mean value for kernel length is observed in cluster 11(6.67) and lowest value in cluster 9(5.46). Cluster 2 (1.93) and cluster 4 (2.32) are having lowest and highest cluster mean for kernel breadth. For L/B ratio, cluster 1 (2.49) and cluster 3 (3.17) are having lowest and highest value respectively. Cluster mean for water uptake is highest in cluster 11 (317) and lowest in cluster 7 (95).

Table.1 Eigen value, contribution of variability, factor for principal component axis

\begin{tabular}{|c|l|l|l|}
\hline Characters & Vector-1 & Vector-2 & Vector-3 \\
\hline Eigen value & 3.47 & 2.69 & 1.41 \\
\hline Variability\% & 28.91 & 22.45 & 11.79 \\
\hline Cumulative \% & 28.91 & 51.37 & 63.16 \\
\hline Hull(\%) & 0.009 & 0.070 & 0.003 \\
\hline Mill(\%) & -0.014 & 0.188 & -0.066 \\
\hline HRR(\%) & 0.044 & 0.234 & -0.021 \\
\hline KL(mm) & -0.067 & -0.239 & 0.380 \\
\hline KB(mm) & -0.010 & 0.473 & -0.414 \\
\hline L/B & -0.017 & -0.220 & 0.211 \\
\hline ASV & -0.398 & 0.592 & 0.615 \\
\hline WU & -0.858 & -0.297 & -0.240 \\
\hline VER & -0.191 & -0.069 & 0.073 \\
\hline KLAC & 0.126 & -0.279 & 0.369 \\
\hline ER & 0.202 & -0.33 & 0.191 \\
\hline AC(\%) & 0.056 & -0.224 & -0.136 \\
\hline
\end{tabular}


Table. 2 Cluster Mean value of 12 quality characters for 100 rice genotypes

\begin{tabular}{|c|c|c|c|c|c|c|c|c|c|c|c|c|}
\hline \multicolumn{3}{|c|}{ Cluster mean } & \multirow[b]{2}{*}{$\operatorname{HRR}(\%)$} & \multirow[b]{2}{*}{$\mathrm{KL}$} & \multirow[b]{2}{*}{ KB } & \multirow[b]{2}{*}{$\mathrm{L} / \mathrm{B}$} & \multirow[b]{2}{*}{ ASV } & \multirow[b]{2}{*}{ WU } & \multirow[b]{2}{*}{ VER } & \multirow[b]{2}{*}{ KLAC } & \multirow[b]{2}{*}{ ER } & \multirow[b]{2}{*}{$\mathrm{AC}(\%)$} \\
\hline $\begin{array}{l}\text { Cluster } \\
\text { no. }\end{array}$ & Hull(\%) & $\operatorname{Mill}(\%)$ & & & & & & & & & & \\
\hline 1 & 78.15 & 70.76 & 58.90 & 5.65 & 2.29 & $2.49 *$ & 4.54 & 131.82 & 3.96 & 9.84 & 1.75 & 23.90 \\
\hline 2 & 78.25 & 66.00 & 52.75 & 5.75 & $1.93^{*}$ & 2.99 & $3.0 *$ & 115.00 & 4.00 & 10.30 & 1.79 & 26.01 \\
\hline 3 & 78.75 & 65.50 & 56.50 & 6.18 & 1.95 & $3.17 * *$ & 3.25 & 95.00 & 4.25 & 10.40 & $1.68 *$ & 27.05 \\
\hline 4 & 78.02 & 71.53 & 59.21 & 5.91 & $2.32 * *$ & 2.63 & 6.92 & 251.71 & 3.95 & 10.46 & 1.78 & 23.61 \\
\hline 5 & $76.63^{*}$ & 69.56 & 57.29 & 5.62 & 2.22 & 2.53 & 3.38 & 241.88 & 4.25 & 10.31 & 1.85 & 25.43 \\
\hline 6 & 79.00 & $72.00 * *$ & $42.50 *$ & 6.58 & 2.18 & 3.02 & 5.00 & 122.50 & 3.88 & 11.55 & 1.76 & 23.20 \\
\hline 7 & 77.00 & $64.50 *$ & 55.00 & 5.60 & 2.09 & 2.65 & 5.25 & $95.00 *$ & 3.88 & 11.10 & 1.99 & $27.90 * *$ \\
\hline 8 & 78.67 & 70.02 & $61.50 * *$ & 5.84 & 2.27 & 2.61 & 3.46 & 122.96 & 3.95 & 10.99 & 1.89 & 23.87 \\
\hline 9 & 78.00 & 69.00 & 53.00 & $5.46^{*}$ & 2.15 & 2.52 & 6.75 & 172.50 & 3.88 & $9.30 *$ & 1.70 & 25.95 \\
\hline 10 & 79.00 & 67.00 & 54.00 & 6.24 & 2.10 & 2.98 & 5.25 & 310.00 & 4.00 & 10.90 & 1.75 & $21.00 *$ \\
\hline 11 & 78.42 & 67.17 & 54.75 & $6.67 * *$ & 2.15 & 3.16 & $7.08 * *$ & $317.00 * *$ & $4.33^{* *}$ & $13.13 * *$ & $2.01 * *$ & 25.73 \\
\hline 12 & $81.25 * *$ & 70.50 & 54.00 & 6.58 & 2.14 & 3.08 & 5.00 & 135.00 & $3.88^{*}$ & 9.60 & 1.80 & 24.85 \\
\hline
\end{tabular}

Table.3 Intra and inter Cluster distances of $\mathrm{D}^{2}$ value in 100 genotypes for 12 quality characters

\begin{tabular}{|c|c|c|c|c|c|c|c|c|c|c|c|c|}
\hline & cl1 & $\operatorname{cl} 2$ & 3 & 4 & 5 & 6 & 7 & 8 & 9 & 10 & 11 & 12 \\
\hline cl1 & (57.2) & 76.67 & 90.89 & 255.04 & 183.21 & 80.17 & 88.87 & 94.47 & 95.10 & 392.22 & 497.03 & 120.81 \\
\hline cl2 & & $(0.0)$ & 10.68 & 476.65 & 201.39 & 89.09 & 59,73 & 78.22 & 158.45 & 475.42 & 598.87 & 113.54 \\
\hline 3 & & & $(0.00)$ & 429.99 & 265.59 & 105.50 & 49.75 & 86.91 & 186.14 & 583.80 & 667.36 & 111.64 \\
\hline 4 & & & & (69.94) & 150.15 & 234.43 & 380.83 & 374.79 & 100.61 & 108.06 & 144.25 & 307.39 \\
\hline 5 & & & & & (48.77) & 210.63 & 294.34 & 247.53 & 126.87 & 136.44 & 244.96 & 262.77 \\
\hline 6 & & & & & & $(0.00)$ & 101.85 & 126.85 & 85.16 & 341.17 & 420.96 & 102.17 \\
\hline 7 & & & & & & & $(0.00)$ & 95.12 & 144.09 & 584.0 & 604.87 & 128.76 \\
\hline 8 & & & & & & & & (100.04) & 193.71 & 511.39 & 615.50 & 162.14 \\
\hline 9 & & & & & & & & & $(0.00)$ & 216.83 & 266.85 & 138.77 \\
\hline 10 & & & & & & & & & & $(0.00)$ & 101.03 & 437.72 \\
\hline 11 & & & & & & & & & & & (86.66) & 520.52 \\
\hline 12 & & & & & & & & & & & & $(0.00)$ \\
\hline
\end{tabular}


Fig.1 Clustering of 100 genotypes in to 12 groups based on 12 quality characters

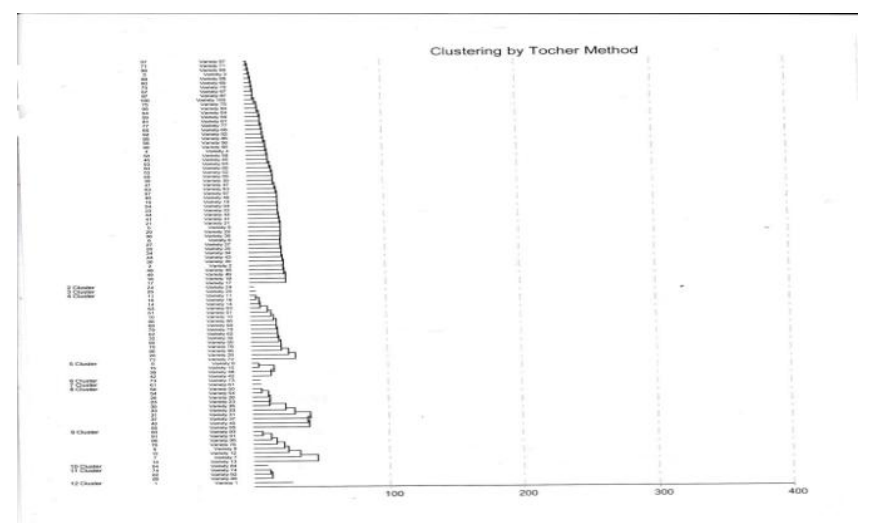

Fig.2 Euclidean distance among 12 clusters

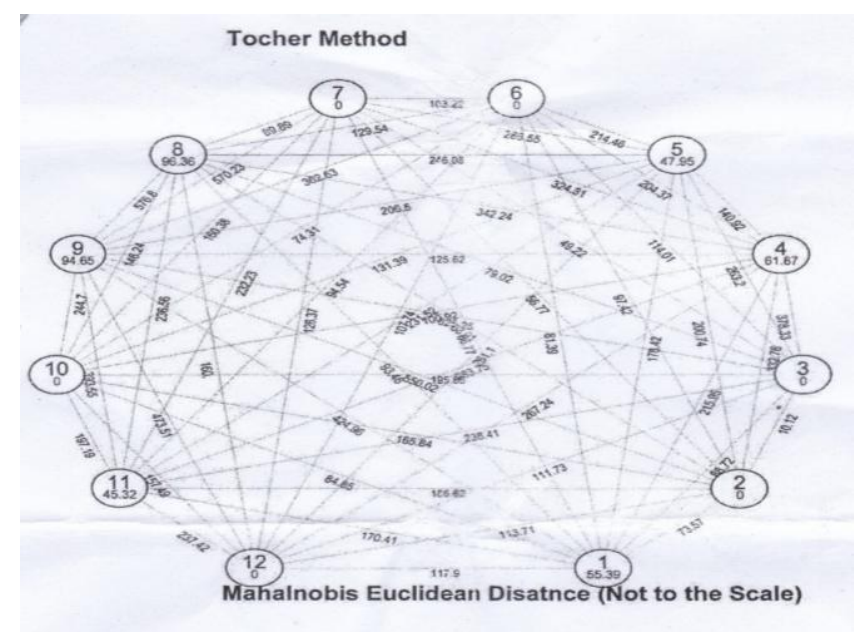

Mean value for Volume expansion ratio is lowest in cluster 12(3.88) and highest in cluster 11(4.33). Cluster mean for KLAC is highest in cluster 11(13.13) and lowest in cluster 9(9.3).Amylose content is highest in cluster 7 (27.9) and lowest in cluster 10(21.0). PCA revealed that three most important components having Eigen value 3.47, 2.69 and 1.41 respectively which accounts for $63.16 \%$ of the total variance for all the characters. Percentage of variance for the 3 factors are 28.91, 22.45 and 11.79 which together account for $63.16 \%$ of the variability of the genotypes used for diversity analysis (table-1).

\section{Acknowledgement}

The authors are thankful to the Director National Rice Research Institute, Cuttack for providing the necessary facility to carry out the study.

\section{References}

Anonymous.2004. Laboratory manual of rice grain quality procedure. Directorate of Rice Research (pp1-20) Rajendranagar, Hyderabad, India.

Asish,K.B., Kalaiyarasi, R.,Thiagarajan, K.\& Manonmani, S.2006.Physico-chemical 
and cooking quality characteristic of promising varieties and hybrids in rice (Oryz asativa L.) Ind.Journ. Genetics 66 (2):107-112.

Azeez, M.H.\&Shafi,M.1966.Quality in rice. Technical bulletin 13(p-50). Department of Agriculture. Govt of West Pakisthan, Lahore.

Beachell, H.M. \& Stansel, I.W.1963.Selecting rice for specific cooking characters in a breeding programme. Int.Rice Comm. Newsl (special issue)25-40.

Bhonsle, S.J.\& Sellapan, K.2010.Grain quality evaluation of traditionally cultivated rice varieties of Goa, India. Recent Research in Sci and Tech. 2(6): 88-97.

Chauhan, J.S., Chauhan, V.S.\&Lodh, S.B.1995.Comparative analysis of variability and correlations between quality components in traditional rain fed upland and lowland rice. Ind. Journ. Gen. Plant breeding 55:6-12.

Das,Sangheeta.\&Borah,S.P.2008. Studies on the genetic component of varieties for yield attributing and quality characters of some traditional rice varieties of Nalbari districts of Assam. Ind.Joun.Crop.Sci.3:103-106.

Fan,J.,Jeibenmorgan, J. J. and Yang, W.A. 2000. Study of head rice yield reduction of long and medium grain varieties in relation to various harvest and drying condition. Transactions of the American society of Agricultural Engineers. 43:1709-1714.

Gannamani,N.2001.Study of heterosis and combining ability by utilising cytoplasmic genetic male sterility and fertility restoration system in rice.(Oryzasativa $\quad$ L.)M.SC(Ag)Thesis IGKV,Raipur.

Gomez, K.A. and Gomez, A.A.1984. Statistical procedure for agricultural research, Newyork john Wiley and Sons.
Govindswamy,S. and Ghosh, A.K.1969.Time of harvest moisture content and method of drying on milling quality of rice. Oryza 6:54-66.

IRRI. 1996.Standard Evaluation Systems for Rice $\left(4^{\text {th }}\right.$ edition) INGER, Genetic resources centre, IRRI, Manila, Philippines.

Itani, T.T., Masahils,A.E and Toshrah,H. 2002.Distribution of amylase, nitrogen and minerals in rice kernel with various characteristics. Journ.Agril.Food.Chem. 50 : $5322-$ 5326.http://dx.doi.org./10.1021/jfo2007 $3 x$.

Jenning, P.R., Coffman, W.R. and Kauffman, H.E.1979.Grain quality (pp101-120) International Rice Improvement. International Rice Research Institute, Manila, Philippines.

Juliano, B.O.1971. A simplified assay for milled rice amylase. Cereal Science Today. 16:334-338,340-360.

Juliano, B.O., Perez, C. M. and Kaosa,M. 1990.Grain quality characteristics of export rice in selected markers. Cereal Chemistry 67: 192-197.

Little, R.R., Hilder, G.B.and Dawson, E.H. 1958.Differential effect of dilute alkali on 25 varieties of milled white rice. Cereal Chemistry 35:111-126.

Merce, F.E. and Juliano, B.O.1981. Physicochemical properties of starch of intermediate amylase and starch.Satake,33:253-260.

Panwar, R.P., Sharma, S.R.K., Arya, K.P.S. and Panwar, A.1997.Genetic variability and interrelationship in rice. (Oryza sativa L.). Advances in Plant Sciences. 10(1): 29-32.

Ramiah, K. 1969.Grain classification (p.629). In. rice research in India,ICAR publication.

Sao,A.2002.Studies on combining ability and heterosis in $\mathrm{F} 1$ rice hybrids using cytoplasmic male sterile lines. 
M.Sc(Ag) Thesis IGKV,Raipur

Sarkar,R.K., Nanda, B.B., Dash,A.B. and Lodh, S.B.1994.Grain characteristics and cooking quality of some aromatic and non aromatic long slender varieties of rice (Oryza sativa L.). Ind.joun.Agril.Sci.64:305-309.

Sarawagi, A.K., Rastogi, N.K.and Soni, D.K.2000.Studies on some quality parameters of indigenous rice in Madhya Pradesh. Annals of Agricultural Research.21(2):258-261.

SobhaRani, N., SubbaRao, L.V., Pandey, M.K., Sudersan,I .and Prasad, G.S.V. 2008. Grain quality variation of physicochemical, milling, and cooking properties of Indian rice (O.sativa L.). Ind.Joun.Crop.Science.

Srivasthava, K., Das,A.,. Pande,K. and Sharma, S.G.2012.Physico-chemical and cooking quality characteristics of some (Oryza sativa L.) genotypes from Faizabad. Ind.Journ. AgricBioche.25(1):68-70.

Subudhi, H.N., Das, S. and Meher, J. 2009.Variability and character association of quality characters in upland rice of eastern India. Bull.PureApplied.Sci.28B(1-2):1-7.

Subudhi, H.N., Das, S., Swain, D., Singh, O.N. and Shrama, S.G.2012.Studies on yield, physic chemical and cooking characters of elite rice varieties (Oryzasativa L.) in eastern India. JournAgril Sci. 4(12): 269-275.

Vanaja, T.and Babu, L.C.2006.Variability in grain quality attributes of high yielding varieties (Oryza sativa L.) of diverse origin. Journal of Tropical Agriculture.44(1-2):61-63.

\section{How to cite this article:}

Subudhi, H. N., J. Meher, S. K. Dash, L. K. Bose, Sutapa Sarkar and Mohapatra, S. 2021. Genetic Diversity Studies of Popular Rice Varieties based on Grain Quality Characters. Int.J.Curr.Microbiol.App.Sci. 10(01): 2974-2980.

doi: https://doi.org/10.20546/ijcmas.2021.1001.344 